\title{
Differentiated Thyroid Cancer in Navarra (Spain): Historic Cohort Results (1987-2003)
}

\author{
María Pilar Salvador Egea, ${ }^{1}$ Ana Aranzazu Echegoyen Silanes, ${ }^{2}$ \\ Eduardo Layana Echezuri, ${ }^{3}$ Emma Anda Apiñariz, ${ }^{4}$ Ana Puras Gil, ${ }^{2}$ \\ Edelmiro Menéndez Torre, ${ }^{5}$ Lluis Forga Llenas, ${ }^{4}$ and Amaya Sainz de los Terreros ${ }^{4}$ \\ ${ }^{1}$ Department of Surgery, Complejo Hospitalario de Navarra, Irunlarrea street 3, 31008 Pamplona, Spain \\ ${ }^{2}$ Department of Pathology, Complejo Hospitalario de Navarra, Irunlarrea street 3, 31008 Pamplona, Spain \\ ${ }^{3}$ Department of Preventive Medicine, Complejo Hospitalario de Navarra, Irunlarrea street 3, 31008 Pamplona, Spain \\ ${ }^{4}$ Department of Endocrinology, Complejo Hospitalario de Navarra, Irunlarrea street 3, 31008 Pamplona, Spain \\ ${ }^{5}$ Department of Endocrinology and Nutrition, Hospital Universitario Central de Asturias, Celestino Villamil Street $s / n$, \\ 33006 Oviedo, Spain
}

Correspondence should be addressed to Amaya Sainz de los Terreros, amaya_st@hotmail.com

Received 17 May 2011; Accepted 14 June 2011

Academic Editors: E. Boven and C. N. Qian

Copyright (C) 2011 María Pilar Salvador Egea et al. This is an open access article distributed under the Creative Commons Attribution License, which permits unrestricted use, distribution, and reproduction in any medium, provided the original work is properly cited.

\begin{abstract}
Introduction. Navarra has the highest incidence of differentiated thyroid cancer in Spain. The aim of this study was to review its management carried out by the Navarra's multidisciplinary Thyroid Disease Unit, from 1987 to 2003. Material and Methods. 325 patients were studied to find the incidence, prevalence, and prognostic factors. Statistical analysis comprised univariate and multivariate Cox proportional hazards regression models for survival and tumor recurrence. Results. The average annual incidence was 3.6 per 100,000 inhabitants, with a final prevalence of 82.4 per 100,000. Regarding survival and recurrence, statistical significance was observed for stage IV, follicular carcinoma, capsular and prethyroid muscles invasion, and T4 group. Only survival was related to tumour size larger than $40 \mathrm{~mm}$. Only recurrence was related to lymph node metastases and radioiodine dose higher than $100 \mathrm{mCi}$. Conclusions. Attendance of patients in a functional unit setting has allowed us to classify them into three risk groups.
\end{abstract}

\section{Introduction}

Differentiated thyroid cancer (DTC) is becoming more frequent. The highest incidence in Spain is found in the region of Navarra [1-3]. Recent research in tyrosine kinase pathogenic activity and inhibitors is becoming more relevant; nowadays, however, related treatments are used only in selected patients [4]. Therefore, currently surgery is the only treatment option that can cure it. If necessary, it can be complemented by radioiodine and suppressive hormone therapy. When very low risk papillary microcarcinoma is detected, it may be sufficient to perform a less extensive surgery [5-8]. On the other hand, when high-risk DTC is found, it is mandatory to complete thyroid intervention with a level VI of Robinson [9] lymphadenectomy because with this approach local recurrence is lower [9-11].
Recent changes in guidelines have modified DTC treatment and long-term follow-up. Recombinant human thyrotropin is widely used to avoid levothyroxine treatment withdrawal in thyroglobulin $(\mathrm{Tg})$ detection. High levels of stimulated $\mathrm{Tg}$ are considered reliable data and the most sensitive one for early diagnosis of persistent/recurrent disease. A high-resolution ultrasound (US) [12] image obtained by an expert provider can supply important information for diagnosis, staging, and follow-up, and it guides fine needle aspiration cytology (FNAC) [13].

In this study, we set the following objectives.

(i) To analyse the incidence and prevalence of DTC in the representative population of the region of Navarra.

(ii) To describe demographic characteristics, tumor characteristics, chosen treatment, and results during 
follow-up (cure, persistent/recurrent disease, and death [14]).

(iii) To evaluate the effect of above-mentioned data on recurrence or mortality, by using statistical analysis.

(iv) To determine prognostic factors; identifying risk groups and, if possible, suggesting criteria focused on the improvement of treatment, management, survival, and low recurrence rate.

Our data have come from the setting of a functional unit, known in our hospital as the "Thyroid Disease Unit." It is composed of a multidisciplinary team of specialists (surgeons, endocrinologists, pathologists, and radiologists) interested in this field. This Unit treats nearly every patient (more than 90\%) suffering from DTC in the public health system of Navarra.

We obtained significant predictive variables in the univariate and multivariate statistical analysis, which are associated with survival and persistent/recurrent disease.

\section{Methods}

Our research is defined as an observational, historic cohorts, descriptive, and analytical study. It includes patients who have been diagnosed with DTC, treated and followed from 1987 until 2003 (17 years) by the Thyroid Disease Unit. From the creation of this unit, data for variables and clinical outcomes have been collected in a database. Following international guidelines, patients were assessed in the outpatient clinic and then the database was updated. The information used was included in the official hospital cancer registry and files, so the process was backed up by local health law and approved by the ethics commitee. Eight patients missed in the follow-up were contacted. They lived in a different region but they were able to provide the required information, therefore they were included in the final results.

In the first five years, our population mean was 518241 people, from 1992 to 1996 it was 520622 people, from 1997 to 2001 it was 567337 people, and the last two years it was 560243 people. In the regional hospital of our area of interest, there was not a public cancer registry available. Nevertheless, we assume that there are few cases detected in it.

Studied variables were as follows.

(i) Gender and age at the time of surgery. We analysed two groups separately; younger than 45 years old and equal/older than 45 years old at that moment, as indicated in TNM [15-17] staging system.

(ii) Result of presurgical FNAC. We discriminated four groups; suspicious, malignant, not valid, and benign cytology.

(iii) Tumor classification; DTC was classified in papillary carcinoma (PC) or follicular carcinoma (FC) comprising Hürthle carcinoma, as recommended by current pathological classification. Then, we counted PC or FC and their pathological variants if available.

(iv) Tumor size, expressed in milimeters. In seven patients, it was not reported, so those were labelled as Tx. (v) Surgical treatment on the thyroid; the kind of surgical procedure of the primary tumor.

(vi) Surgical treatment of cervical lymph node metastases; number of lymphadenectomies performed.

(vii) Surgical complications with in-patients, once they arrived at the surgical ward, were compiled. The most important and frequent ones were recurrent nerve palsy and definitive hypocalcemia after parathyroid injury. Asphyctic hematoma was not included because it usually happens few hours after surgery, and it is managed by anaesthetics.

(viii) TNM staging system at the time of diagnosis. We used the 6th edition PTNM system.

(ix) Thyroid capsule invasion; whether the primary tumor infiltrates into the glandular capsule, meaning an advanced stage, or not.

(x) Cervical muscle involvement by the primary tumor.

(xi) Unifocal or multifocal tumor in the gland; number of malignant locations in the thyroid.

(xii) Radioiodine treatment; number of treatment sessions and total cumulative dose of I-131 in each patient.

(xiii) Positive antithyroglobulin autoantibodies; number of patients affected.

The descriptive study of all these items was executed in a first instance. Later, statistical models were built for analysis of data: univariate model for survival, univariate model for persistent/recurrent disease, multivariate model for survival, and multivariate model for persistent/recurrent disease, always using Proportional Risks Cox Regression. We also show survival curves and the 5- and 10-year survival rates of significant variables. The outcomes of recurrence and persistent disease are grouped together due to their low incidence (below 4\%). Also, by doing such statistical analysis it is easier to develop and to understand. The software chosen was SPSS 17.0 for Windows.

\section{Results}

325 patients underwent surgical treatment for their DTC $(100 \%)$. Annual incidence resulted in 3.6 per 100000 inhabitants, and prevalence was 82.4 per 100000 inhabitants at the time of December 2003.

The ratio for women reached $80 \%$. Our population can be considered young, given that $52.61 \%$ were under 45 years old. The presurgical FNAC result was suspicious or malignant in $75 \%$. Regarding tumor classification, PC was diagnosed in $63.38 \%$, with a mean age of 42.90 years old (range 12 to 79 years old) and mean tumor size of $21.75 \mathrm{~mm}$ (range 1 to $80 \mathrm{~mm}$ ). In FC, mean age was 49.56 years old (range 15 to 83 years old) and mean tumor size was $40.89 \mathrm{~mm}$ (range 10 to $100 \mathrm{~mm}$ ). Tumor size was below $40 \mathrm{~mm}$ in $79 \%$ and below $20 \mathrm{~mm}$ in $42 \%$.

Total thyroidectomy with any kind of lymphadenectomy was the surgical procedure in $95.69 \%$, detecting positive lymph nodes in $21.23 \%$ of them. Surgical complications 
collected were as follows: $4 \%$ definitive recurrent nerve palsy, $1.8 \%$ definitive hypoparathyroidism, and $0.3 \%$ surgical wound infection.

Most patients belonged to early tumoral stages; $78.46 \%$ were included in stages I and II of TNM system. Details of T and $\mathrm{N}$ distribution and stages are shown in Table 1.

Thyroid capsules were affected in nearly $13 \%$, and in 37 subjects, cervical muscle involvement was reported. Multifocal tumors were found in $32.61 \%$.

Radioiodine treatment was used for $97.53 \%$ individuals.

About autoimmunity, we detected positive antithyroglobulin antibodies in 22 patients, with the following characteristics: $90 \%$ PC, mean tumor size of $25.9 \mathrm{~mm}$, mean age of 39.5 years old, positive cervical lymph nodes in $59 \%$, and recurrent disease in $9 \%$.

During follow-up, patients were considered to be free of disease when symptoms were absent, physical examination was negative as were image exams, and Tg was undetectable together with thyrotropin higher than $30 \mathrm{mUI} / \mathrm{L}$ and negative antibodies. $77.55 \%$ of patients fulfilled these criteria. On the other hand, $4 \%$ of patients have died ( 8 with PC and 5 with $\mathrm{FP})$ and $3.69 \%$ presented with recurrent disease.

Finally, the final $14.76 \%$ corresponded to subjects that had some biochemical abnormality during follow-up, usually a single elevation of thyroglobulin, but could not be included in the cured group nor in those who had tumor evidence on radiology exams. Distant metastases were detected in $9(2.8 \%)$ patients. The most frequent target was lung; 8 patients ( $89 \%$ of metastatic disease). In four of them, lung metastases coexisted with bone ( 3 patients) or brain (1 patient) location. One patient diagnosed of multiple metastatic sites suffered from subcutaneous spread. Every distant spread was diagnosed after first surgical treatment. The summary of descriptive data is shown in Table 1.

In the univariate model for survival, we found statistical significance in the variables; capsule invasion, prethyroid muscle involvement, tumor size larger than $40 \mathrm{~mm}$, T4 group of TNM (with regard to the T1 group and to the "rest of T" group: $\mathrm{T} 1+\mathrm{T} 2+\mathrm{T} 3$ ), and stage IV (with regard to the "rest of stages"). They predicted a higher risk of mortality. Results are shown in Table 2.

In the univariate model for recurrent disease, we also found statistical significance in the variables; capsule invasion, prethyroid muscle involvement, positive cervical lymph nodes, T4 group of TNM (with regard to the T1 group and to the "rest of T" group; T1+T2+T3), and stage IV (with regard to the stage I and to the "rest of stages"), and total cumulative dose of radioiodine higher than $100 \mathrm{mCi}$. Results are shown in Table 3.

In the multivariate model for survival, higher mortality was related to stage IV compared to the "rest of stages" and related to FC compared to PC. Results are shown in Table 4. Survival curves are represented in Figures 1 and 2.

In the multivariate model for recurrent disease, higher risk of recurrence was observed in patients with prethyroid muscle involvement, positive cervical lymph nodes, and FC compared to PC. Results are shown in Table 5.

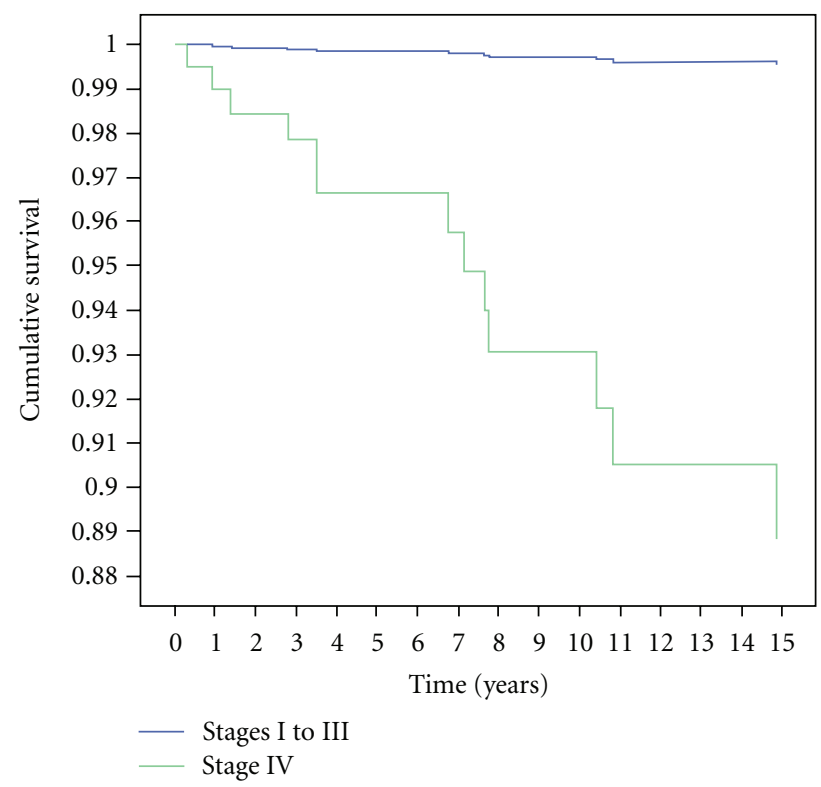

FIgure 1: Survival curve of stage IV and rest of stages in the multivariate analysis.

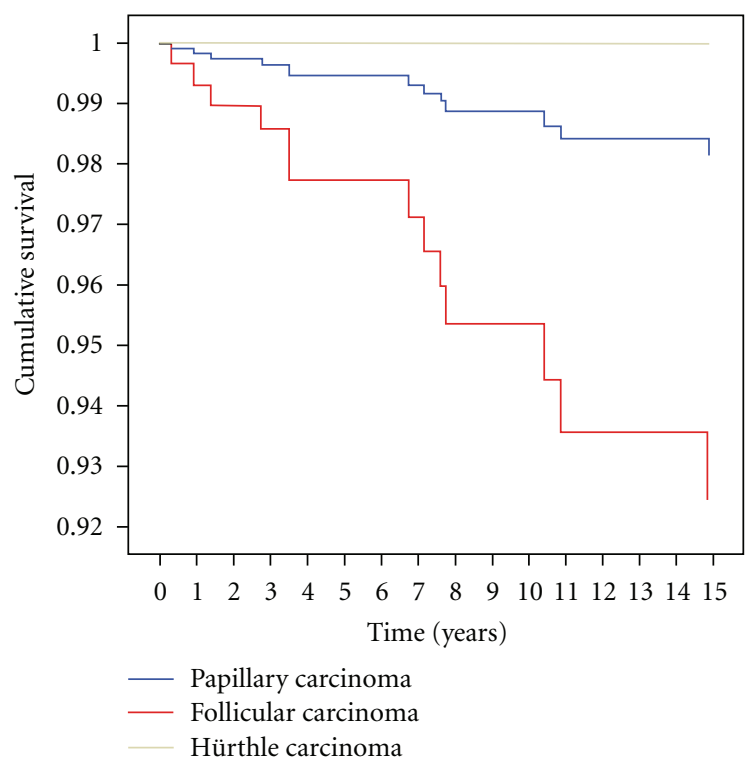

Figure 2: Survival curve of pathological classification in the multivariate analysis.

The 5-year survival rate and the 10-year survival rate of each significant variable are given in Table 6.

\section{Discussion}

In Spain, the highest incidence of DTC has been described in the region of Navarra. Values adjusted for age are 3.10 and 9.36 per 100000 inhabitants/year in men and women respectively, between 1987 and 1997. In Germany, France, and Italy [1], similar results were obtained due to early diagnosis and thorough analysis of surgical tissues. 
TABLE 1: General overview of main descriptive results.

\begin{tabular}{|c|c|}
\hline Variables and their classifications & Ratio \\
\hline Age: younger than 45 years old & $52.61 \%$ \\
\hline Gender: women & $80.00 \%$ \\
\hline Presurgical FNAC: suspicious or malignant & $75.00 \%$ \\
\hline \multicolumn{2}{|l|}{ Tumor pathological classification: } \\
\hline (i) Papillary carcinoma (mean age 42.90 years old, mean tumor size $21.75 \mathrm{~mm}$ ) & $63.38 \%$ \\
\hline (ii) Follicular carcinoma (mean age 49.56 years old, mean tumor size $40.89 \mathrm{~mm}$ ) & $36.61 \%$ \\
\hline Surgical treatment on the thyroid: total thyroidectomy & $95.69 \%$ \\
\hline Surgical treatment of cervical lymph node metastases & $21.23 \%$ \\
\hline \multicolumn{2}{|l|}{ Surgical complications: } \\
\hline (i) Recurrent nerve palsy & $4.00 \%$ \\
\hline (ii) Definitive hypoparathyroidism & $1.80 \%$ \\
\hline \multicolumn{2}{|l|}{ TNM classification: } \\
\hline (i) T1: 125 patients & $38.46 \%$ \\
\hline (ii) $\mathrm{T} 2: 97$ patients & $29.84 \%$ \\
\hline (iii) T3: 61 patients & $18.76 \%$ \\
\hline (iv) $\mathrm{T} 4: 42$ patients & $12.92 \%$ \\
\hline (v) N0: 256 patients & $78.76 \%$ \\
\hline (vi) N1: 69 patients & $21.23 \%$ \\
\hline \multicolumn{2}{|l|}{ Stages: } \\
\hline (i) I: 207 patients & $63.69 \%$ \\
\hline (ii) II: 48 patients & $14.76 \%$ \\
\hline (iii) III: 40 patients & $12.30 \%$ \\
\hline (iv) IV: 30 patients & $9.23 \%$ \\
\hline (a) IV a: 21 patients & $6.40 \%$ \\
\hline (b) IV c: 9 patients & $2.80 \%$ \\
\hline (v) Stage I and II & $78.46 \%$ \\
\hline Radioiodine treatment & $97.53 \%$ \\
\hline Positive antithyroglobulin autoantibodies & $6.77 \%$ \\
\hline Complete remission & $77.55 \%$ \\
\hline Mortality & $4.00 \%$ \\
\hline Persistent/recurrent disease & $3.69 \%$ \\
\hline
\end{tabular}

FNAC: fine needle aspiration cytology.

TABLE 2: Univariate model for survival.

\begin{tabular}{|c|c|c|c|c|}
\hline \multirow{2}{*}{ Univariate model for survival } & \multirow{2}{*}{$P$} & \multirow{2}{*}{ Hazard ratio } & \multicolumn{2}{|c|}{ HR 95\% CI } \\
\hline & & & Lower & Upper \\
\hline Age & 0.056 & 79.9 & 0.8 & 7157.7 \\
\hline Thyroid capsule invasion & 0.000 & 9.2 & 3.1 & 27.5 \\
\hline Muscle involvement & 0.000 & 12.1 & 4.0 & 36.4 \\
\hline Tumor size; $>40 \mathrm{~mm}$ versus $<20 \mathrm{~mm}$ & 0.033 & 10.3 & 1.2 & 88.3 \\
\hline T4 versus $\mathrm{T} 1(\mathrm{TNM})$ & 0.003 & 24.1 & 2.9 & 195.9 \\
\hline $\mathrm{T} 4$ versus rest of $\mathrm{T}(\mathrm{TNM})$ & 0.000 & 10.9 & 3.4 & 34.5 \\
\hline Stage IV versus rest of stages & 0.000 & 20.3 & 6.6 & 62.3 \\
\hline
\end{tabular}

Our research included patients diagnosed, treated, and followed for 17 years in a Thyroid Disease Unit. Therefore, we got quite a good number of subjects and the management by a functional unit made possible to use identical protocols and to initiate little changes according to current external guidelines. Also, patients dying because of their DTC may have died during those 17 years and recurrences or persistent disease should have been evident, because two thirds of those situations appear within the 10 years following surgery $[16,17]$. That long-term follow-up is a positive aspect of our study to bear in mind [14].

In relation to gender, we were able to prove that women were more affected $(80 \%)$, with a women/men ratio of $4 / 1$, somewhat higher than previously described; Ponce Marco 
TABLE 3: Univariate model for persistent/recurrent disease.

\begin{tabular}{|c|c|c|c|c|}
\hline \multirow{2}{*}{ Univariate model for persistent/recurrent disease } & \multirow{2}{*}{$P$} & \multirow{2}{*}{ Hazard ratio } & \multicolumn{2}{|c|}{ HR 95\% CI } \\
\hline & & & Lower & Upper \\
\hline Thyroid capsule invasion & 0.000 & 5.3 & 2.7 & 10.2 \\
\hline Muscle involvement & 0.000 & 6.9 & 3.6 & 13.4 \\
\hline Positive lymph nodes & 0.000 & 3.7 & 1.9 & 7.0 \\
\hline T4 versus T1 (TNM) & 0.000 & 4.3 & 2.0 & 9.4 \\
\hline T4 versus rest of $\mathrm{T}$ (TNM) & 0.000 & 5.4 & 2.8 & 10.5 \\
\hline Stage IV versus rest of stages & 0.001 & 3.5 & 1.6 & 7.4 \\
\hline
\end{tabular}

TABLE 4: Multivariate model for survival.

\begin{tabular}{|c|c|c|c|c|c|}
\hline \multirow{2}{*}{ Multivariate model for survival. } & \multirow{2}{*}{$B$} & \multirow{2}{*}{$P$} & \multirow{2}{*}{ Hazard ratio } & \multicolumn{2}{|c|}{ HR 95\% CI } \\
\hline & & & & Lower & Upper \\
\hline Stage IV versus rest of stages & 3.284 & 0.000 & 26.674 & 8.643 & 82.322 \\
\hline Follicular versus papillary ca. & 1.439 & 0.012 & 4.216 & 1.366 & 13.008 \\
\hline Hürthle versus papillary ca. & -13.556 & 0.983 & 0.000 & 0.000 & \\
\hline
\end{tabular}

TABLE 5: Multivariate model for persistent/recurrent disease.

\begin{tabular}{|c|c|c|c|c|c|}
\hline \multirow{2}{*}{ Multivariate model for persistent/recurrent disease } & \multirow{2}{*}{$B$} & \multirow{2}{*}{$P$} & \multirow{2}{*}{ Hazard ratio } & \multicolumn{2}{|c|}{ HR 95\% CI } \\
\hline & & & & Lower & Upper \\
\hline Muscle involvement & 1.851 & 0.000 & 6.366 & 3.106 & 13.047 \\
\hline Positive lymph nodes & 1.154 & 0.002 & 3.172 & 1.520 & 6.619 \\
\hline Follicular versus papillary ca. & 0.821 & 0.049 & 2.274 & 1.005 & 5.146 \\
\hline
\end{tabular}

TABLE 6: Survival rates of significant variables.

\begin{tabular}{lcc}
\hline Variable & $\begin{array}{c}\text { 5-year } \\
\text { survival rate } \\
(\%)\end{array}$ & $\begin{array}{c}10 \text {-year } \\
\text { survival rate } \\
(\%)\end{array}$ \\
\hline Stage IV & 96.7 & 93 \\
Rest of stages & 99.9 & 99.8 \\
Follicular carcinoma & 97.7 & 95.3 \\
Papillary carcinoma & 99.5 & 98.8 \\
Thyroid capsule invasion & 92 & 85 \\
Thyroid capsule not invaded & 99 & 98 \\
Muscle involvement & 90 & 82 \\
Muscle not involved & 99 & 98 \\
Tumor size $>40$ mm & 95.5 & 94 \\
Tumor size $<20$ mm & 99.6 & 99.3 \\
T4 (TNM) & 91.5 & 86 \\
Rest of T (TNM) & 99.5 & 99 \\
T1 (TNM) & 99.6 & 99.3 \\
\hline
\end{tabular}

[2] and Sitges Serra and Sancho Inserser [3] have reported a ratio of $2 / 1$, without providing any explanation for differences. Gender distribution in the general population cannot justify it because in Navarra and in their region it is similar. Even though female life expectancy is longer than male's in our area, DTC [18-23] was detected mainly in young people.
Most of the people were young. Scheiden et al. [24] have observed similar data in Luxemburg (1990-1999); 310 subjects had a mean age of 48.3 years old, with a PC increase from 1997 due to an early diagnosis in opinion of the authors. Our association between age and survival was nearly statistically significant. Given that more than $50 \%$ were younger than 45 years old and none of them had died during follow-up, we obtained a distorted statistical model. So, we propose that young age could have an important positive predictive value on survival.

Regarding diagnosis, FNAC is considered the test of choice by expert panels $[2,3]$. In our work, it has been malignant or suspicious in $75 \%$, with an increased value when performed in recent years probably because highresolution US [25] was introduced for early detection of local recurrence, for diagnosis of lymph node metastases, and for guiding FNAC [26]. At the end of the study, we obtained a false positive result in $1 \%$ and a false negative result in $5 \%$.

In our patients, most tumors were PC. However, we found a more elevated rate of FC than in previous studies $[2,3,18-23,27]$. Its cause remains unknown to us. Perhaps it could be explained by a higher prevalence of FC in immigrants or stronger environmental factors for goiter in some areas of our region. We advise supplementing diet with iodine and updating epidemiological research focused on understanding it.

We did not find statistical association between surgical procedure and survival. Except for 14 patients, in every case total thyroidectomy was executed, with subsequent 
radioiodine treatment if needed and hormone suppression [28].

The number of lymphadenectomies registered is not too high (66 cases). Nevertheless, we must remember that routine cervical level VI dissection in papillary carcinoma was widely accepted not long before this study was finished. For Mazzaferri and Kloos [29], mediastinal and cervical bilateral lymph node metastases modify recurrences and survival as independent predictors and specific surgery on lymph areas improves those items. In our series, cervical lymph node metastases impair recurrences but not survival. This tumor stage has traditionally been treated surgically, both in the initial diagnosis and lymph node recurrence.

Surgical morbidity keeps on being a worrying topic. Sancho Fornos et al. [23] have published a meta-analysis about benign and malignant goiter surgery; in best series, he found $1.5 \%$ nerve injury and $0-2 \%$ definitive hypocalcemia. But when level VI lymphadenectomy is associated, nerve injury rises to $3-4 \%$ and hypocalcemia reaches $14-17 \%$. In our work, there is an intermediate morbidity in relation to those previous results. We believe that factors that might contribute are the observational nature of the study (historic cohort), several surgeons and resident surgeons implicated in treatment, and the later recommendation of level VI lymph node dissection [30].

Looking back to the relevance of age within stages and early diagnosis for prognosis, it is worthwhile remembering that more than half of the population were under 45 years old. Moreover, diagnosis came earlier in most cases $(63.69 \%$ belong to stage I). These circumstances may explain the survival for both kinds of DTC. Our survival rate can be related to previous works; Beasley et al. [31] have reported no deaths in stage I and a mean age in patients dying from their DTC of 68.5 years old.

Interpretation of negative effect of a radioiodine treatment dose over $100 \mathrm{mCi}$ on persistent disease can be understood because more aggressive tumors force us to use higher doses of it. Also recurrences are treated with several sessions of radioiodine and in that way the total dose is increased. Even though this variable showed statistical significance as mentioned before, we do not include it in Table 3 because of the chronological opposite relationship. Analysis of positive antithyroglobulin antibodies did not reach statistical significance, maybe because of the low sample size. However, those tumors seemed to be more aggressive after studying descriptive data.

Studying outcomes according to former characteristics, every subject developing persistent/recurrent disease was diagnosed with PC (12 cases). Ten of them were under 45 years old. Within related aggressive factors, we can describe 6 patients with worse PC variants (2 of tall-cells and 4 of diffuse sclerosant), 7 with positive cervical lymph adenopathies at diagnosis, 5 with thyroid capsule infiltration, 5 were multifocal tumors, and 5 with prethyroid muscle involvement. In all of them, persistent/recurrent disease consisted of locoregional spread (thyroid bed and cervical lymphadenopathies), and so were surgically treated. Stojadinovic et al. [32] have reported the follow-up of 431 recurrent DTC during 13 years, finding a 35\% local recurrence, $23 \%$ local and regional recurrence, and 30\% local and distance recurrence. Symptoms were evident only in $26 \%$. They conclude that survival can be predicted by age under 45 years old, subclinical or local recurrence, and the ability of maintaining the disease-free situation. Mazzaferri and Jhiang [14] have published a follow-up of 30 years and show a survival of $76 \%$ and $30 \%$ recurrences. Mortality increased every decade over 40 years old. The recurrent disease appeared more often in age under 20 and over 59 years old. In our series, DTC was the cause of death in every patient suffering from distant metastases. We counted 13 (4\%) DTC total deaths; 9 (2.8\%) with distant disease and $5(1.5 \%)$ with local recurrence. Only one patient died suffering from local and distant recurrence. When patients showed symptoms or were classified in stage IV at the time of diagnosis, we observed the above-mentioned bad prognosis. This group had a mean age of 68.3 years old.

Some workshops and expert panels have suggested risk classifications, both through a few parameters for grouping patients and through many clinical data providing complex systems [33, 34]. Probably, the most used risk classification for clinicians during follow-up is the one based on basal or stimulated $\mathrm{Tg}$ detection. Mazzaferri et al. [33] have defined a group of disease-free patients when $\mathrm{Tg}$ is below $0.5 \mathrm{ng} / \mathrm{mL}$ (60-70\% of patients), a group of patients needing close follow-up if $\mathrm{Tg}$ is 0.6 to $2 \mathrm{ng} / \mathrm{mL}(15-20 \%)$, and a group likely to show local or distant recurrence or persistent disease if Tg is over $2 \mathrm{ng} / \mathrm{mL}$ (20-25\%). Schlumberger et al. [34] have also supplied risk factors for recurrence; tumor size larger than $20 \mathrm{~mm}$ and/or with cervical locoregional spread. Prospective studies have shown that patients with undetectable $\mathrm{Tg}$ and negative cervical US show a less $0.5 \%$ risk of 10-year recurrence rate. Sánchez Franco [13] has demonstrated that this risk increases as tumoral stage does. This statement can be considered a brief general concept, present in many studies.

\section{Conclusions}

Our results allow us to classify patients in three risk groups defined as follows.

(i) A group with a better long-term prognosis would be composed of subjects younger than 45 years old, with PC diagnosed in FNAC, and with DTC detected in early stages ( $\mathrm{T} 1$ to $\mathrm{T} 3$, smaller than $40 \mathrm{~mm}$, negative cervical lymph nodes and without capsule or muscle involvement).

(ii) A group with a higher risk of recurrent disease, but not higher mortality, would be represented by those patients with positive cervical lymph nodes and those who have received a total cumulative dose of radioiodine more elevated.

(iii) A group with higher risk of recurrence and death would be composed of patients of 45 years old or older, with FC and advanced stage (stage IV, T4 or larger than $40 \mathrm{~mm}$, with capsule or muscle invasion). 
In our opinion, this classification could help in guiding treatment and follow-up; frequency of out-patient visits and need of complementary examinations, being aware of methodological limits from any observational research.

\section{Conflict of Interests}

None of the authors presents any conflict of interests.

\section{References}

[1] V. L. Carvajal and M. P. Santamaría, "Epidemiología del cáncer diferenciado de tiroides," Endocrinologia y Nutricion, vol. 52, no. 1, pp. 2-10, 2005.

[2] J. L. Ponce Marco, "Cáncer de tiroides," in Cirugía AEC: Manual de la Asociación Española de Cirujanos, J. L. L. Garcia, Ed., chapter 67, pp. 630-645, Médica Panamericana, Madrid, Spain, 1st edition, 2005.

[3] A. Sitges Serra and J. Sancho Inserser, "Carcinoma diferenciado de tiroides, carcinoma medular de tiroides, carcinoma anaplásico de tiroides y linfoma tiroideo," in Guías Clínicas de la Asociación Española de Cirujanos, A. S. Serra and J. S. Inserser, Eds., Cirugía Endocrina, chapter 2, pp. 27-50, Arán Ediciones, Madrid, Spain, 1st edition, 1999.

[4] G. Riesco-Eizaguirre and P. Santisteban, "Molecular biology of thyroid cancer initiation," Clinical and Translational Oncology, vol. 9, no. 11, pp. 686-693, 2007.

[5] M. Schlumberger, G. Berg, O. Cohen et al., "Follow-up of low-risk patients with differentiated thyroid carcinoma: a European perspective," European Journal of Endocrinology, vol. 150, no. 2, pp. 105-112, 2004.

[6] E. M. Torre, M. T. L. Carballo, R. M. R. Erdozáin, L. F. Llenas, M. J. G. Iriarte, and J. J. B. Layana, "Prognostic value of thyroglobulin serum levels and ${ }^{131}$ I whole-body scan after initial treatment of low-risk differentiated thyroid cancer," Thyroid, vol. 14, no. 4, pp. 301-306, 2004.

[7] B. Biondi, S. Filetti, and M. Schlumberger, "Thyroidhormone therapy and thyroid cancer," Nature clinical practice. Endocrinology \& Metabolism, vol. 1, no. 1, pp. 32-40, 2005.

[8] S. I. Sherman, P. Angelos, D. W. Ball et al., "Thyroid carcinoma," Journal of the National Comprehensive Cancer Network, vol. 3, no. 3, pp. 404-457, 2005.

[9] A. L. Jiménez and A. S. Serra, "Cáncer diferenciado de tiroides. Avance en el tratamiento quirúrgico," Endocrinología y Nutrición, vol. 52, pp. 11-17, 2005.

[10] A. Machens and H. Dralle, "Decreasing tumor size of thyroid cancer in Germany: institutional experience 1995-2009," European Journal of Endocrinology, vol. 163, no. 1, pp. 111$119,2010$.

[11] A. Machens and H. Dralle, "Failure to consider the number of dissected sides can bias complication rate calculations of central lymph node dissection for thyroid cancer," Archives of Surgery, vol. 145, no. 10, pp. 1026-1027, 2010.

[12] A. Frasoldati, M. Pesenti, M. Gallo, A. Caroggio, D. Salvo, and R. Valcavi, "Diagnosis of neck recurrences in patients with differentiated thyroid carcinoma," Cancer, vol. 97, no. 1, pp. 90-96, 2003.

[13] F. Sánchez Franco, "Directrices en el tratamiento del carcinoma diferenciado de tiroides," Endocrinologia y Nutricion, vol. 52, no. 1, pp. 23-31, 2005.

[14] E. L. Mazzaferri and S. M. Jhiang, "Long-term impact of initial surgical and medical therapy of papillary and follicular thyroid cancer," American Journal of Medicine, vol. 97, no. 5, pp. 449$500,1994$.

[15] J. Rosai, M. L. Carcangiu, A. Ronald, and M. D. Delellis, Atlas of Tumor Pathology: Tumors of Parathyroid Glands, 3rd series, Armed Forces Institute of Pathology, Washington, DC, USA, 1992.

[16] F. Pacini, M. Schlumberger, H. Dralle, R. Elisei, J. W. A. Smit, and W. Wiersinga, "European consensus for the management of patients with differentiated thyroid carcinoma of the follicular epithelium," European Journal of Endocrinology, vol. 154, no. 6, pp. 787-803, 2006.

[17] D. Cooper, G. Doherthy, B. Haugen et al., "Manegement guidelines for patients with thyroid nodules and differentiated thyroid cancer. American Thyroid Asociation," Thyroid, vol. 16, no. 2, pp. 109-142, 2006.

[18] R. L. Witt and A. M. McNamara, "Prognostic factors in mortality and morbidity in patients with differentiated thyroid cancer," Ear, Nose and Throat Journal, vol. 81, no. 12, pp. 856863, 2002.

[19] A. R. Zambudio, J. M. Rodríguez, R. Moya et al., "Los alelos HLA-CW7 y CW1 como factores de mal pronóstico en el carcinoma diferenciado de tiroides en el sudeste español," Cirugia Espanola, vol. 72, no. 2, pp. 44-45, 2002.

[20] B. K. Kinder, "Well differentiated thyroid cancer," Current Opinion in Oncology, vol. 15, no. 1, pp. 71-77, 2003.

[21] E. L. Mazzaferri, "Long-term outcome of patients with differentiated thyroid carcinoma: effect of therapy," Endocrine Practice, vol. 6, no. 6, pp. 469-476, 2000.

[22] E. L. Mazzaferri, "An overview of the management of papillary and follicular thyroid carcinoma," Thyroid, vol. 9, no. 5, pp. 421-427, 1999.

[23] S. Sancho Fornos, J. V. Urbaneja, J. L. P. Marco, R. P. Jiménez, and C. H. Vela, "Complicaciones de la cirugía tiroidea," Cirugia Espanola, vol. 69, no. 3, pp. 198-203, 2001.

[24] R. Scheiden, M. Keipes, and C. Bock, "Thyroid cancer in Luxembourg: a national population-based data report (19831999)," BioMed Central Cancer, vol. 24, no. 6, pp. 100-102, 2006.

[25] S. Sheth and U. M. Hamper, "Role of sonography after total thyroidectomy for thyroid cancer," Ultrasound Quarterly, vol. 24, no. 3, pp. 147-154, 2008.

[26] T. Rago and P. Vitti, "Role of thyroid ultrasound in the diagnostic evaluation of thyroid nodules," Clinical Endocrinology and Metabolism, vol. 22, no. 6, pp. 913-928, 2008.

[27] S. I. Sherman, "Thyroid carcinoma," The Lancet, vol. 361, no. 9356, pp. 501-511, 2003.

[28] A. R. Shaha, "Implications of prognostic factors and risk groups in the management of differentiated thyroid cancer," Laryngoscope, vol. 114, no. 3, pp. 393-402, 2004.

[29] E. L. Mazzaferri and R. T. Kloos, "Current approaches to primary therapy for papillary and follicular thyroid cancer," Journal of Clinical Endocrinology and Metabolism, vol. 86, no. 4, pp. 1447-1463, 2001.

[30] A. R. Ready and A. D. Barnes, "Complicaciones de la tiroidectomía," British Journal of Surgery, vol. 81, no. 11, pp. 15551556, 1994.

[31] N. J. P. Beasley, P. G. Walfish, I. Witterick, and J. L. Freeman, "Cause of death in patients with well-differentiated thyroid carcinoma," Laryngoscope, vol. 111, no. 6, pp. 989-991, 2001.

[32] A. Stojadinovic, M. Shoup, A. Nissan et al., "Recurrent differentiated thyroid carcinoma: biological implications of age, method of detection, and site and extent of recurrence," Annals of Surgical Oncology, vol. 9, no. 8, pp. 789-798, 2002. 
[33] E. L. Mazzaferri, R. J. Robbins, C. A. Spencer et al., "A consensus report of the role of serum thyroglobulin as a monitoring method for low-risk patients with papillary thyroid carcinoma," Journal of Clinical Endocrinology and Metabolism, vol. 88, no. 4, pp. 1433-1441, 2003.

[34] M. Schlumberger, F. Pacini, W. M. Wiersinga et al., "Followup and management of differentiated thyroid carcinoma: a European perspective in clinical practice," European Journal of Endocrinology, vol. 151, no. 5, pp. 539-548, 2004. 


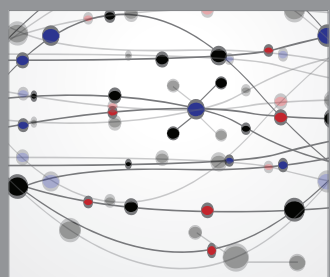

The Scientific World Journal
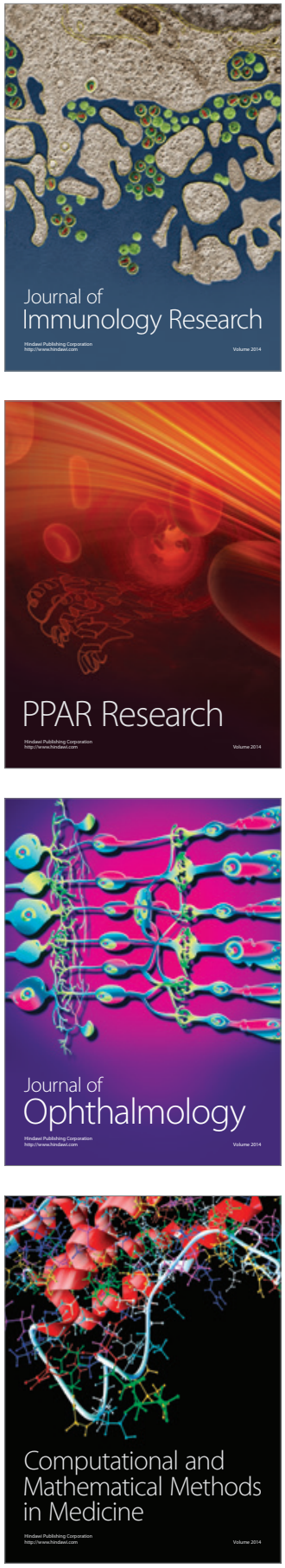

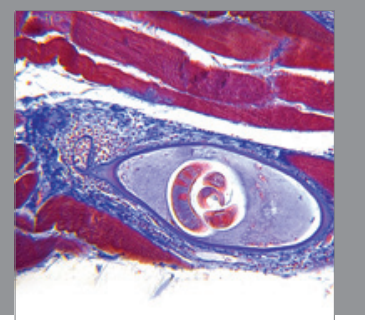

Gastroenterology

Research and Practice
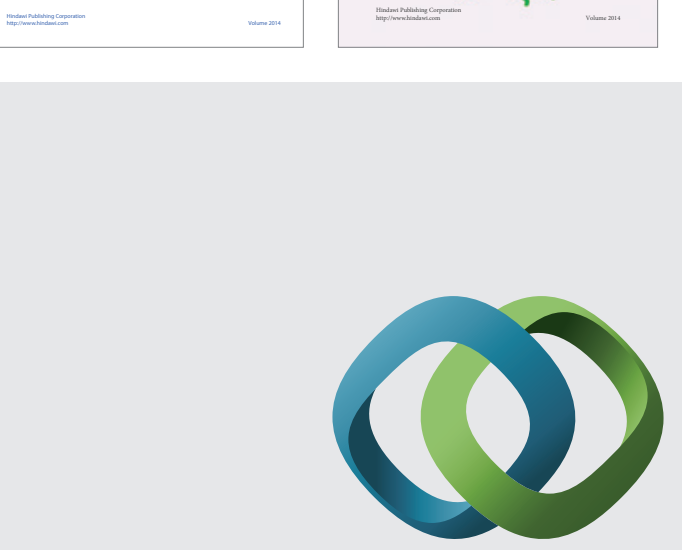

\section{Hindawi}

Submit your manuscripts at

http://www.hindawi.com
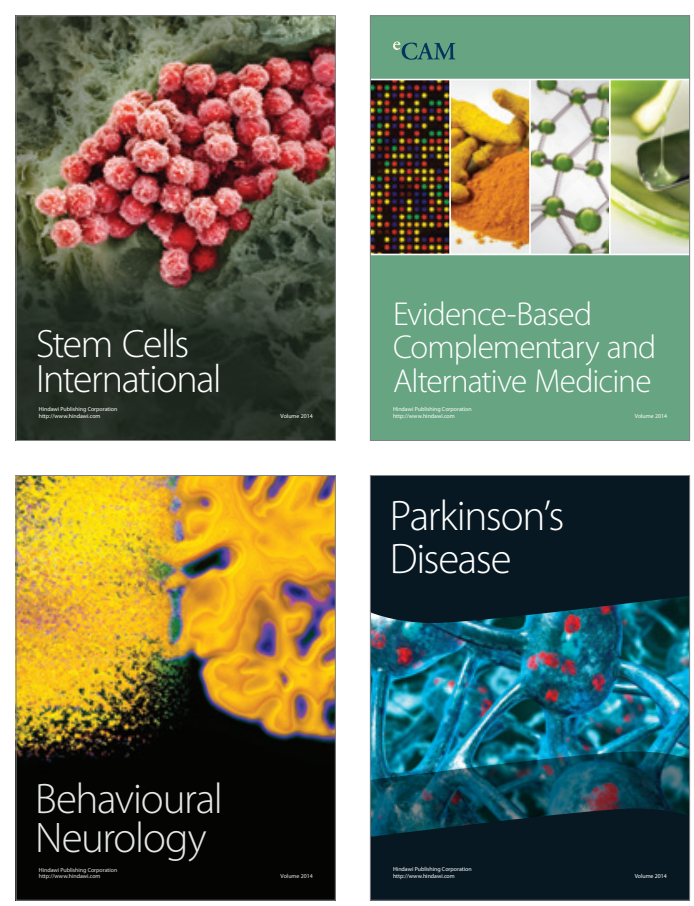

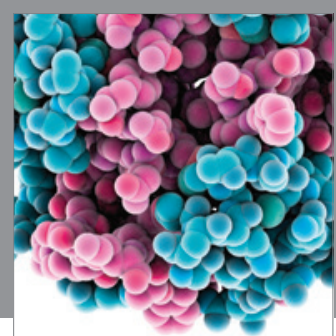

Journal of
Diabetes Research

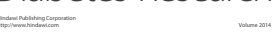

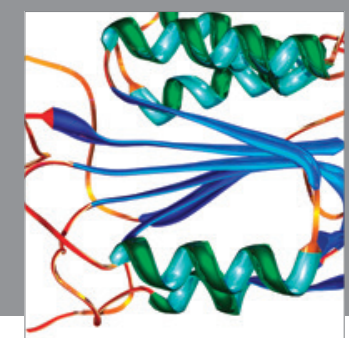

Disease Markers
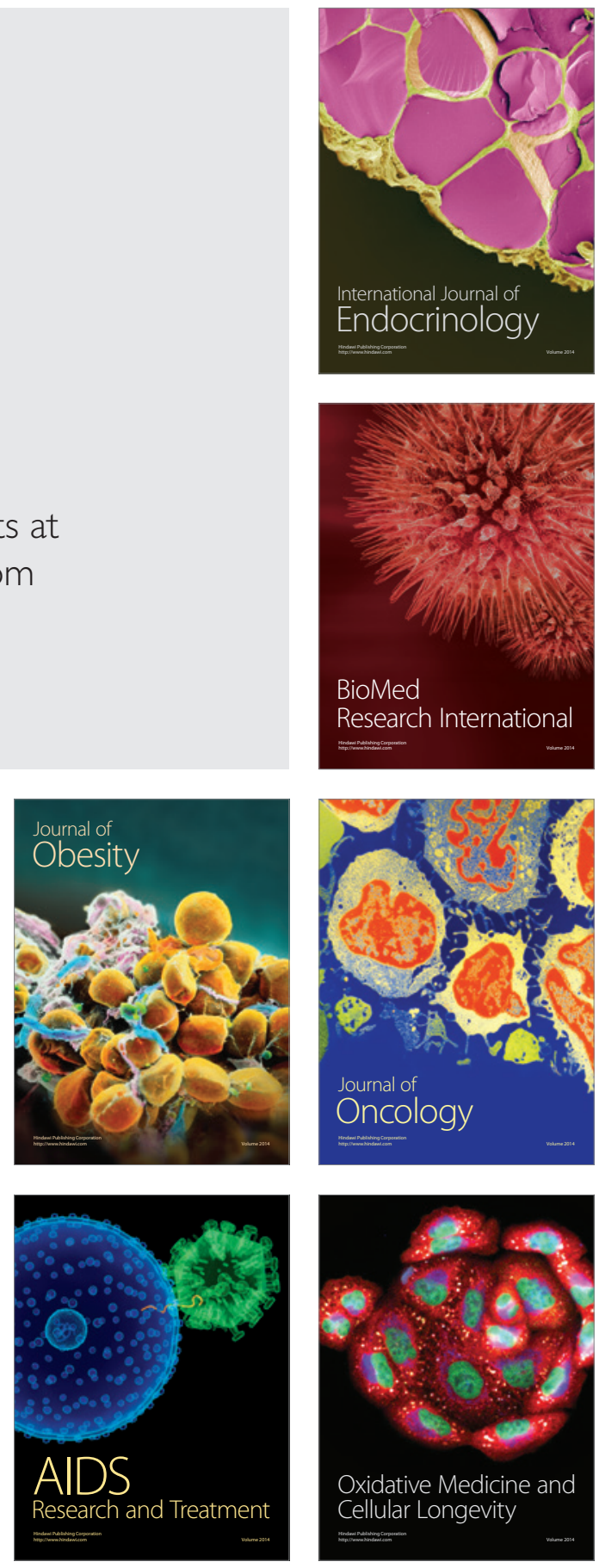